\title{
A Case-Control Study for Assessing Risk Factors for Congenital Anomalies among Children in Sulaimani City
}

\author{
Niaz Mustafa Kamal \\ Anesthesia Department \\ Technical Collage of health \\ Sulaimani Polytechnic University \\ Sulaimani, Iraq \\ niaz.Kamal@spu.edu.iq
}

\author{
Nasih Othman \\ Kurdistan institute for Strategic Studies \\ and Scientific Research \\ Sulaimani Iraq \\ nasih.othman@kissr.edu.krd
}

\begin{abstract}
Congenital anomalies comprise a wide range of abnormalities in body structure or function that are present at birth and are of prenatal origin. These are defined as structural changes that have significant medical, social or cosmetic consequences for the affected individual, and typically require medical intervention. According to our Knowledge, research is scarce on these conditions in Sulaimaniyah city. Therefore, the current study was conducted to investigate potential risk factors for congenital anomalies. A case-control study was carried out from March to August 2017 involving 400 children (200 cases and 200 controls) aged 0-5 years. Required data were obtained on the risk factors through face to face interviews with mothers of cases and controls. The data were using descriptive statistical methods, Chi-square and Logistic Regression using STATA 11, calculating odds ratios and condensing $P$ value less than 0.05 as statistically significant. The mean age of the children was 1.9 years and age of their mothers at the time of pregnancy was 28 years. Congenital heart anomalies were the commonest type accounting for $27.5 \%$. Significant risk factors for congenital anomalies were family history $(O R=2.24, P=0.007)$, maternal obesity $(O R=2.26, P=0.001)$, mothers age over $30(O R=2.78$, $P=0.002)$ and mothers not using folic acid during pregnancy $(O R=2.12, P=0.0007)$. In general, in order to control and prevent the cases of $C M$, it is important to provide health education and policies to reduce environmental and maternal risk factors. Further, studies with larger sample size are needed to investigate incidence and risk factors of congenital anomalies.
\end{abstract}

Keywords: Sulaimani, Anomalies, Down syndrome, consanguinity, Microcephaly, Cleft lip.

\section{INTRODUCTION}

Congenital anomalies or birth defects are defined as "structural or functional anomalies (for example, metabolic disorders) that occur during intrauterine life and can be identified prenatally, at birth, or sometimes may only be detected later in infancy, such as hearing defects" [1]. Early intrauterine period (between the $3^{\text {rd }}$ and the $8^{\text {th }}$ weeks of gestation) is the vital period of life for the normal development of organs, any problem within that period may result in congenital malformations [2]. Congenital anomalies are among the leading causes of infant mortality and morbidity around the world responsible for over 300,000 neonatal deaths in 2015[1]. The effect of birth defects is mainly severe in the middle- and low-income countries where health care resources are limited compared to high-income countries $[3,4]$. The long-term disability caused by congenital anomalies may have a significant impact not only on a child's well-being and development but also on families, health care systems and societies[2]. Congenital anomalies are classified into two types of defects includes minor and major defects, The most common major structural birth defects include congenital heart disease (CHD), neural tube defects, orofacial clefts and limb reduction defects[5]. Generally, congenital anomalies that involve the CNS and the cardiovascular and musculoskeletal systems have been reported to be the most common [2]. The congenital anomalies may be caused by genetic $(30-40 \%)$ or environmental factors $(5-10 \%)$ and approximately $50 \%$ of all congenital anomalies cannot be linked to a specific cause[6]. Among genetic causes, chromosomal abnormality makes up about $6 \%$, single gene disorders about $25 \%$, and multifactorial about $20-30 \%$. In about $50 \%$ of cases, the cause is unknown[4]. Potential risk factors that have contributors to congenital malformations includes low socioeconomic and parents educational levels, malnutrition (micronutrient and macronutrient), maternal infections ( e.g. diabetes and rubella), lack of environmental protection policies, unsafe working conditions during pregnancy, medication use during pregnancy, common use of home remedies of unknown composition and chemical household cleaners[5]. In addition, growth restriction, preterm delivery, mother's age and weight during pregnancy and parental consanguinity are also associated with birth defects [7, 8]. Furthermore, it has been reported that there is an association between environmental exposures such as air pollution, alcohol consumption, environmental tobacco smoking, radiation, pesticides and pregnancy outcomes such as pregnancy loss, stillbirth, fetal growth, preterm birth and congenital anomalies [9-11]. There have been no studies on the risk factors associated with birth defects in Sulaimani; therefore, the current study was 
undertaken to determine the risk factors associated with congenital anomalies in the governorate.

\section{METHODS AND MATERIALS}

The participants of this hospital-based case-control study were children aged 0-5 years as well as their mothers. Data were collected from Sulaimani Pediatric and Maternity Teaching Hospitals in addition to 3 private hospitals as Zhyan, Harem, and International Hospital. A total of 400 children ( 200 cases of congenital anomalies and 200 controls without congenital anomalies) were included in the study, and data were collected from their mothers interviewed between March and October 2017. The Pediatric Teaching Hospitals provides a wide range of health services for children and infants, while Maternity and Private Hospitals provide care for pregnant women including deliveries in the city. the cases were enroled by recruiting all newborn infants and children with congenital anomalies attending the hospital for follow up or for other reasons during the study period. Meanwhile, 200 children without congenital anomalies attending the Pediatric Teaching Hospital for others diseases or who were born healthy during the same period of study were selected as controls randomly depending on the list of daily admission to the ward. Inclusion criteria were Any child aged 0-5 years and resident in Sulaimani city were eligible for inclusion in both cases and controls. Maternal age was categorized as $\leq 25$ years, 26-35 years and $\geq 35$ years; maternal BMI was categorized as $18.5-24 \mathrm{~kg} / \mathrm{m}^{2}$ (normal weight), 25-29 $\mathrm{kg} / \mathrm{m}^{2}$ (overweight) and $\geq 30 \mathrm{Kg} / \mathrm{m}^{2}$ (obese); gestational age of 39-41 weeks as full-term and $\leq 38$ weeks as preterm [12] . The information on mother's weight during pregnancy was collected from antenatal care booklet issued by the health centers. The children variables analyzed were birth weight, categorized as $<2500$ grams (low birth weight) and $\geq 2500$ grams (normal weight). Information on the risk factors was collected from face to face interview with mother/caregivers after explaining the aims of the study was done for the mother's cases an controls and obtaining informed consent. Privacy and confidentiality were respected. The study did not involve any harmful intervention to the children and their mothers. The study was approved by the ethics committee of Technical College of Health and permission was also taken from all hospitals. Obtained data were statistically analyzed using descriptive statistical methods (frequency, percentage, mean and standard deviation). Chi-square test was applied to compare categorical variables, and odds ratios were calculated for potential risk factors using logistic regression in Stata version 11. P value equal to and less than 0.05 was considered statistically significant for all analysis and smaller $\mathrm{P}$ values were reported as $<0.001$ if they were smaller than 0.001 .

\section{RESULTS}

The sample included 200 cases with different anomalies (100 boys and 100 girls) and 200 controls without congenital anomalies (110 boys and 90 girls) with the mean age of 1.9 (SD 1.5) years. The mean maternal age at the time of pregnancy was 28 year (SD 6.1). A number of sociodemographic characteristics of the children cases and controls are demonstrated in Table 1. There was no significant association between gender, ethnicity, mother's occupation, mother's education and consanguineous marriage with congenital anomalies. There were similar numbers of cases from inside and outside the city $(49.5 \%$ VS. $50 \%)$, while in the control $63.5 \%$ were from inside and $36.5 \%$ were from outside of Sulaimani city. majority of cases and controls were of Kurdish ethnicity (95\% of cases and $91.5 \%$ of controls). Majority of mothers in cases and controls were unemployed (80.5\% VS. 87\%). Among cases, $80.5 \%$ of mothers were educated and $19.5 \%$ were not while in controls this was $86 \%$ VS. $14 \%$. With respect to family history, $19 \%$ of cases had child relative with CM while this was only $9.5 \%$ in cases and the difference was statistically significant $\left(\chi^{2}: 7.4, \mathrm{P}=0.007\right)$. Figure 1 summarizes the pattern of congenital anomalies seen in the children. The congenital heart diseases were the most common (27.5\%) followed by Down syndrome(20.5\%). While microcephaly, imperforate anus and macrocephaly were the least common types $(3 \%, 2.5 \%$, and $2 \%$ ) respectively.

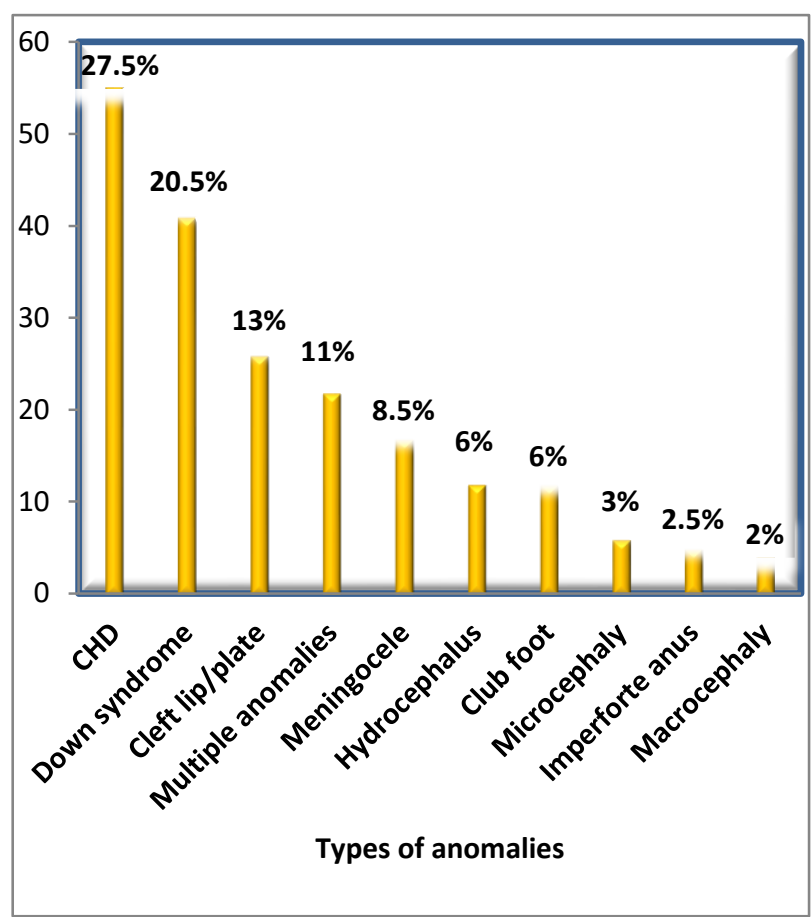

Figure 1: Frequency distribution of congenital anomalies.

The distribution of pregnancy and environmental risk factors of exposed cases and controls are shown in Table 2. As seen from this table, higher maternal age, Obesity, gestational diabetes, low birth weight, preterm delivery, exposure to radiation and failure to take folic acid during pregnancy were significantly associated with the presence of congenital anomalies in the child.

Table 3 shows crude odds ratios for potential risk factors. Children who had a relative with $\mathrm{CM}$ were 2 times at greater risk of being born with congenital malformations compared to those who didn't have relative with $\mathrm{CM}(\mathrm{OR}=2.24, \mathrm{p}=0.007)$. Low birth weight was a highly statistically significant risk factor for the development of $\mathrm{CM}$ with $(\mathrm{OR}=2.85)$ compared to children born with normal weight $(\mathrm{P}<0.0001)$. Premature children had 2 times greater risk of being born with $\mathrm{CM}$ 
compared to full-term children $(\mathrm{OR}=1.88, \mathrm{p}=0.02)$. This result also indicates that higher maternal age is associated with an increased risk of CM as children of mothers aged 26-35 and 36 years and older had an odds ratio of $(2.78, \mathrm{P}=0.002)$ and $(1.6, \mathrm{P}=0.01)$ respectively compared to mothers aged 25 years and younger.

Amongst mothers who have gestational diabetes the odds ratio for having a child with $\mathrm{CM}$ was 9 , compared to those who did not have gestational diabetes (OR 9.37, $\mathrm{P}=0.01$ ). Children born to mothers who did not use folic acid during pregnancy were more prone to having $\mathrm{CM}$ compared to those born to mothers who used folic acid $(\mathrm{OR}=2.12, \mathrm{P}=0.0007)$.

Compared with normal weight mothers (BMI 18.5-24), overweight and obese mothers were at a higher risk of having children with $\mathrm{CM}(\mathrm{OR} 1.96, \mathrm{P}=0.05$; OR 2.26, $\mathrm{P}=0.001$ ) respectively.

Adjusted odds ratios were calculated to control for confounding in pairs of variables related to each other including maternal age and child's order, the presence of a sibling with $\mathrm{CM}$ and consanguineous marriage, child relative with $\mathrm{CM}$ and consanguineous marriage, premature birth and low birth weight and gestational age and BMI during pregnancy (table 4). When we adjusted for consanguinity, family history remained significantly associated with CM (aOR: 2.32, CI: 1.22-4.06, P0.007). With respect to premature birth and low birth weight, after we adjusted for premature birth, low birth weight remained as statistically significantly associated with CM (aOR:1.73, CI:1.20-2.49 P0.003). Moreover, when adjusted for low birth weight, premature birth also remained highly significantly associated with $\mathrm{CM}$ (adjusted OR 2.69, CI: 1.62-4.45, $\mathrm{P}<0.0001$ ). In addition, when adjusted for obesity, gestational diabetes remained a significant risk factor for $\mathrm{CM}$ with an odds ratio of 10.67 (95\% CI: 1.06-106.5, P0.01). Similarly, when adjusted for gestational diabetes, overweight and obese mothers during pregnancy remained at a significantly higher risk of having a child with $\mathrm{CM}$ with an odds ratio of 1.67 (95\% CI 1.0-2.8, P 0.05), 2.30 (95\% CI 1.38-3.86, $\mathrm{P}$ 0.001) respectively.

Table 1: Distribution of cases and controls mothers with socio-demographic characteristics

\begin{tabular}{|c|c|c|c|c|}
\hline Characteristics & $\begin{array}{c}\text { Exposed Cases (200) } \\
(\mathrm{N} \%)\end{array}$ & $\begin{array}{c}\text { Exposed Controls (200) } \\
(\mathbf{N} \%)\end{array}$ & Chi-square & $P$ value \\
\hline \multicolumn{5}{|l|}{ Gender } \\
\hline Male & $100(50)$ & $110(55)$ & 1.0 & 0.3 \\
\hline Female & $100(50)$ & $90(45)$ & & \\
\hline \multicolumn{5}{|l|}{ Residence } \\
\hline Inside sulaimani & $99(49.5)$ & $127(63.5)$ & 7.8 & 0.005 \\
\hline Outside sulaimani & $101(50.5)$ & $73(36.5)$ & & \\
\hline \multicolumn{5}{|l|}{ Ethnicity } \\
\hline Kurd & $190(95)$ & $183(91.5)$ & 1.95 & 0.2 \\
\hline Arab & $10(5)$ & $17(8.5)$ & & \\
\hline \multicolumn{5}{|l|}{ Mother's occupation } \\
\hline Employed & $39(19.5)$ & $26(13)$ & 3.10 & 0.08 \\
\hline Unemployed/ housewife & $161(80.5)$ & $174(87)$ & & \\
\hline \multicolumn{5}{|l|}{ Mother's education } \\
\hline Education & $161(80.5)$ & $172(86)$ & 2.17 & 0.1 \\
\hline Non-education & $39(19.5)$ & $28(14)$ & & \\
\hline \multicolumn{5}{|l|}{ Consanguineous marriage } \\
\hline Yes & $79(39.5)$ & $68(34)$ & 1.30 & 0.3 \\
\hline No & $121(60.5)$ & $132(66)$ & & \\
\hline \multicolumn{5}{|l|}{ History of anomalies in the family } \\
\hline Positive & 38 (19) & $19(9.5)$ & 7.39 & 0.007 \\
\hline Negative & $162(81)$ & $181(90.5)$ & & \\
\hline \multicolumn{5}{|l|}{ Others child with CM } \\
\hline Siblings & $7(3.5)$ & $5(2.5)$ & 0.35 & 0.6 \\
\hline None & $193(96.5)$ & $195(97.5)$ & & \\
\hline
\end{tabular}

Table 2: Distribution of pregnancy and environmental risk factors of cases and controls

\begin{tabular}{|c|c|c|c|c|c|}
\hline & Characteristics & $\begin{array}{c}\text { Cases } \\
\text { Number }(\%) \\
\end{array}$ & $\begin{array}{l}\text { Controls } \\
\text { Number (N \%) }\end{array}$ & Chi-square & P value \\
\hline \multirow{3}{*}{$\begin{array}{l}\text { Pregnancy } \\
\text { risk factors }\end{array}$} & $\begin{array}{l}\text { Mode of delivery } \\
\text { Normal vaginal delivery } \\
\text { Caesarean section } \\
\end{array}$ & $\begin{array}{l}97(48.7) \\
102(51.3)\end{array}$ & $\begin{array}{l}101(50.5) \\
99(49.5)\end{array}$ & 0.12 & 0.7 \\
\hline & $\begin{array}{l}\text { Mother's age } \\
\quad \leq 25 \\
26-35 \\
\geq 36\end{array}$ & $\begin{array}{l}58(29) \\
109(54.5) \\
33(16.5) \\
\end{array}$ & $\begin{array}{l}88(44) \\
94(47) \\
18(9) \\
\end{array}$ & 11.68 & 0.003 \\
\hline & Gestational weight BMI Kg/m ${ }^{2}$ & & & & \\
\hline
\end{tabular}




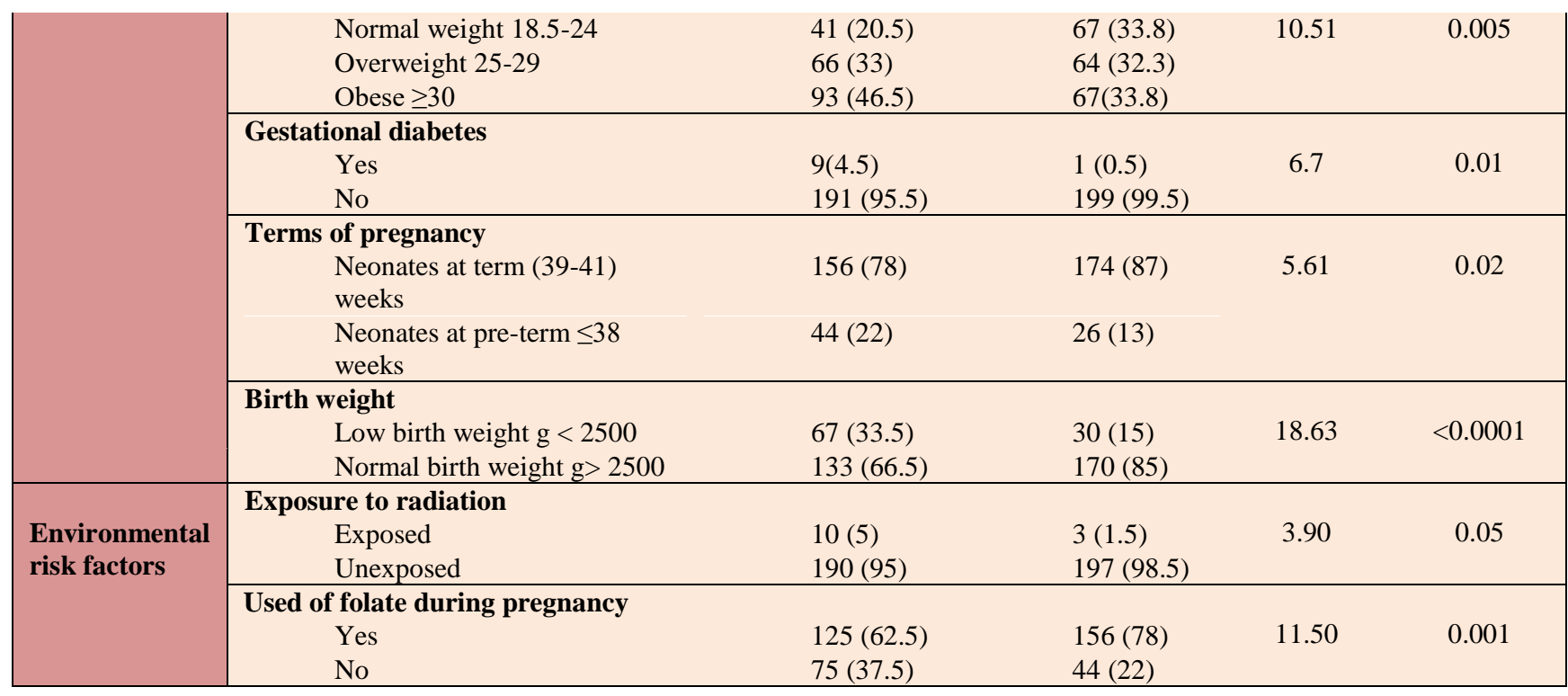

Table 3: Maternal exposed to Sociodemographic and pregnancy risk factors of a child with congenital anomalies

\begin{tabular}{|c|c|c|c|c|}
\hline Risk factors & Odds ratio & $(95 \% \mathrm{CI})$ & Chi Square & $P$ value \\
\hline $\begin{array}{l}\text { Consanguineous marriage } \\
\text { No } \\
\text { Yes } \\
\end{array}$ & $\begin{array}{c}\text { Reference } \\
1.27 \\
\end{array}$ & $(0.84-1.81)$ & 1.30 & 0.3 \\
\hline $\begin{array}{c}\text { Sibling with CM } \\
\text { No } \\
\text { Yes } \\
\end{array}$ & $\begin{array}{c}\text { Reference } \\
1.42\end{array}$ & $(0.44-4.54)$ & 0.34 & 0.6 \\
\hline $\begin{array}{l}\text { Exposure to X-ray } \\
\text { Unexposed } \\
\text { Exposed }\end{array}$ & $\begin{array}{c}\text { Reference } \\
3.45\end{array}$ & $(0.92-12.58)$ & 3.9 & 0.05 \\
\hline $\begin{array}{c}\text { Gestational weight BMI Kg/m } \mathbf{m}^{2} \\
\text { Normal weight } 18.5-24 \mathrm{Kg} / \mathrm{m}^{2} \\
\text { Overweight } 25-29 \mathrm{Kg} / \mathrm{m}^{2} \\
\text { Obese } \geq 30 \mathrm{Kg} / \mathrm{m}^{2} \\
\end{array}$ & $\begin{array}{c}\text { Reference } \\
1.69 \\
2.26 \\
\end{array}$ & $\begin{array}{c}(1.0-2.84)(1.36- \\
3.8) \\
\end{array}$ & $\begin{array}{l}3.89 \\
10.5 \\
\end{array}$ & $\begin{array}{c}0.05 \\
0.001 \\
\end{array}$ \\
\hline $\begin{array}{l}\text { The family history of anomalies } \\
\text { Negative } \\
\text { Positive }\end{array}$ & $\begin{array}{c}\text { Reference } \\
2.24\end{array}$ & $(1.23-4.05)$ & 7.37 & 0.007 \\
\hline $\begin{array}{l}\text { Birth weight } \\
\text { Normal birth weight }>2500 \mathrm{~g} \\
\text { Low birth weight }<2500\end{array}$ & $\begin{array}{c}\text { Reference } \\
2.85 \\
\end{array}$ & $(1.73-4.70)$ & 18.85 & $<0.0001$ \\
\hline $\begin{array}{l}\text { Terms of pregnancy } \\
\text { Neonates at term }(39-41) \text { weeks } \\
\text { Neonates at pre-term } \leq 38 \text { weeks }\end{array}$ & $\begin{array}{c}\text { Reference } \\
1.88\end{array}$ & $(1.11-3.22)$ & 6.5 & 0.02 \\
\hline $\begin{array}{l}\text { Mother's age during pregnancy } \\
\leq 25 \\
26-35 \\
\geq 36 \\
\end{array}$ & $\begin{array}{c}\text { Reference } \\
1.6 \\
2.78 \\
\end{array}$ & $\begin{array}{c}(1.13-272) \\
(1.4-5.50)\end{array}$ & $\begin{array}{l}6.62 \\
9.44 \\
\end{array}$ & $\begin{array}{c}0.01 \\
0.002 \\
\end{array}$ \\
\hline $\begin{array}{l}\text { Gestational diabetes } \\
\text { No } \\
\text { Yes } \\
\end{array}$ & $\begin{array}{c}\text { Reference } \\
9.37\end{array}$ & $(1.15-76.21)$ & 6.6 & 0.01 \\
\hline $\begin{array}{l}\text { Used of folate during pregnancy } \\
\text { Yes } \\
\text { No }\end{array}$ & $\begin{array}{c}\text { Reference } \\
2.12\end{array}$ & $(1.36-3.33)$ & 11.47 & 0.0007 \\
\hline
\end{tabular}

Table 4: Adjusted odds ratio and $95 \%$ confidence intervals for risk factors significantly associated with congenital malformation

\begin{tabular}{|c|c|c|c|c|}
\hline Risk factors & Adjusted Odds ratio & $P$ value & $95 \% \mathrm{CI}$ & Trend $P$ value \\
\hline \multicolumn{5}{|c|}{ Family history anomalies adjusted for consanguinity } \\
\hline No & Reference & & & \\
\hline Yes & 2.23 & 0.007 & $1.22-4.06$ & 0.007 \\
\hline \multicolumn{5}{|c|}{ Premature birth adjusted for low birth weight } \\
\hline Neonates at term (39-41) weeks & Reference & & & \\
\hline Neonates at pre-term $\leq 38$ weeks & 1.73 & 0.003 & $1.20-2.49$ & 0.003 \\
\hline
\end{tabular}


Low birth weight adjusted for premature birth

Normal weight

Low birth weight

Gestational diabetes, adjusted for BMI during pregnancy No

Yes

$\mathrm{BMI}\left(\mathrm{Kg} / \mathrm{m}^{2}\right)$ during pregnancy adjusted for gestational

diabetes

Normal weight $18.5-24 \mathrm{Kg} / \mathrm{m}^{2}$

Overweight $25-29 \mathrm{Kg} / \mathrm{m}^{2}$

Obese $\geq 30 \mathrm{Kg} / \mathrm{m}^{2}$

\section{Reference}

2.69

$<0.0001$

$1.62-4.45$

Reference

10.67

0.01

$1.06-106.5$

$<0.0001$

0.01

Reference

$\begin{array}{lll}1.67 & 0.05 & 1.0-2.8 \\ 2.30 & 0.001 & 1.38-3.86\end{array}$

\section{DISCUSSION}

Congenital anomalies are one of the most prevalent causes of mortality in children. The study shows a raised risk of congenital anomalies in children whose mothers exposed to potential risk factors as environmental and reproductive risk factors. Our study finds a number of risk factors that associated with congenital anomalies as higher maternal age, gestational diabetes, low birth weight, child relatives and not suing tonic drugs during. Our study reported that congenital heart disease and Down syndrome were the most common types of congenital anomalies compared to other types[13-15]. The result of the present study showed that the being borne with low birth weight $(<2500$ grams $)$ was significantly increased the possibility of developing congenital anomalies. In the study conducted Northwest Iran has been showed that children borne with low birth weight are a convincing factor in developing CMs [16]. Major congenital malformations were significantly associated with family history. In a case-control study conducted in Pakistan, family history was reported as one of the main risk factors of CMs in infants[17]. Also in study surveillance survey was done in Albama reported the family history significantly increased the chance of infants being born with CM [18]. We found when family history adjusted for consanguinity remained significantly associated with the presence of $\mathrm{CM}$ in children the aOR 2.23 and the (P 0.007). In accordance with the studies were conducted in Northern Africans, Southeast Asians and Central Americans [19]. Among the maternal characteristics, prematurity $(<37$ completed weeks) was a significant risk factor which is similar to studies done in United State and England [20, 21]. When these variables combining ( premature birth and low birth weight), the adjusted OR was 1.73 (95\% CI 1.224.06). Also birth weight and premature birth, the adjusted OR was 2.96 (95\% CI 1.62-4.45), the two variable remained significantly associated with the developing of $\mathrm{CM}$ among children cases. Which is similar to the two study were done in England and Northwest Iran [16, 21]. Our study also found that increased maternal age is a strong risk factor related to $\mathrm{CM}$ in comparison with younger mothers which is similar to the studies was done in the United State[22, 23]. Maternal consumption of tonic drug as folic acid during pregnancy is a protective factor for decreased risk for having children with CM. Similar to the study conducted in Netherland which reported that folic acid intake during pregnancy lowers the risk of children being born with CM [24]. The result of the present study found that mothers with diabetes Mellitus were 9 times at greater risk of having children with congenital malformations. This in line with the study done in University of Chile Clinical Hospital reporting gestational diabetes associated with CM [25]. Hence, more attention should be taken to the control of diabetes especially during the first trimester of pregnancy. We found a woman who was overweight or obese were significantly had at greater risk for giving birth to infants with CM compared to the normal weight women. Mothers with diabetes and increased weight during pregnancy were giving birth with congenital anomalies, we found this result was statistically significant when we adjusted the variables BMI with diabetes the aOR10.67 (95\% CI 1.06-106.5). Likewise, when we adjusted diabetes with BMI also remained statistically significant with $\mathrm{CM}$ among overweight and obese women the aOR 1.67(95\% CI 1.0-2.8), aOR 2.30 (95\% CI 1.38-3.86) respectively [26, 27]. A systemic review and metaanalysis were done at Newcastle University and a population-based cohort study in Sweden reported that increased mothers weight during pregnancy was related to $\mathrm{CM}[28,29]$. The results of the study reported that parental consanguinity is not associated with the presence of CM which is on the contrary with the study was done Islamic Republic of Iran [30]. This difference could be due to a sample size. Logistics regression analysis also confirmed that risk factors were an independent risk factor for congenital anomalies.

Our study is not without limitations. The probability of selection bias especially in the selection of controls exists. There is also the probability of information bias (recall bias) in collecting information form mothers. The study does not include all possible risk factors which limit comparison with other studies. Therefore, further studies are required to investigate a wider range of risk factors.

\section{CONCLUSION}

Congenital malformations are a common health problem in the region; the congenital heart defects being the most common. Based on the results of this study, the most important and significant risk factors for developing CM are prematurity, family history, maternal obesity, low birth weight, higher maternal age, gestational diabetes and not using folate during pregnancy. In order to improve the child and newborn health and control and reduce congenital anomalies, it is necessary to plan programs and policies for decreasing these risk factors, providing a proper counseling, recognizing dangerous pregnancies, prompt management of maternal illness, and improving antenatal care. 


\section{ACKNOWLEDGMENT}

The authors would like to thank all hospitals staffs and participants mothers for their cooperation and help in completing this study.

\section{REFERENCE}

W. H. Organization. (Updated September 2016). Congenital anomalies Available: http://www.who.int/mediacentre/factsheets/fs370/en/

[2] F. Mashuda, A. Zuechner, P. L. Chalya, B. R. Kidenya, and M. Manyama, "Pattern and factors associated with congenital anomalies among young infants admitted at Bugando medical centre, Mwanza, Tanzania," BMC Res Notes, vol. 7, p. 195, Mar 292014.

[3] R. Sharma, "Birth defects in India: Hidden truth, need for urgent attention," Indian J Hum Genet, vol. 19, pp. 125-9, Apr-Jun 2013.

[4] F. Behjati, S. Ghasemi Firouzabadi, K. Kahrizi, R. Kariminejad, I. Bagherizadeh, J. Ansari, et al., "Chromosome abnormality rate among Iranian patients with idiopathic mental retardation from consanguineous marriages," Arch Med Sci, vol. 7, pp. 321-5, Apr 2011.

[5] R. S. Kishimba, R. Mpembeni, and J. Mghamba, "Factors associated with major structural birth defects among newborns delivered at Muhimbili National Hospital and Municipal Hospitals in Dar Es Salaam, Tanzania 2011 2012," Pan Afr Med J, vol. 20, 2015.

[6] H. A. Obu, J. M. Chinawa, N. D. Uleanya, G. N. Adimora, and I. E. Obi, "Congenital malformations among newborns admitted in the neonatal unit of a tertiary hospital in Enugu, South-East Nigeria - a retrospective study," BMC Res Notes, vol. 5, p. 177, 2012.

[7] W. H. Al Bu Ali, M. H. Balaha, M. S. Al Moghannum, and I. Hashim, "Risk factors and birth prevalence of birth defects and inborn errors of metabolism in Al Ahsa, Saudi Arabia," Pan Afr Med J, vol. 8, 2011.

[8] E. A. L. Gianicolo, A. Bruni, E. Rosati, S. Sabina, R. Guarino, G. Padolecchia, et al., "Congenital anomalies among live births in a polluted area. A ten-year retrospective study," BMC Pregnancy Childbirth, vol. 12, p. $165,2012$.

[9] M. L. Watkins, S. A. Rasmussen, M. A. Honein, L. D. Botto, and C. A. Moore, "Maternal obesity and risk for birth defects," Pediatrics, vol. 111, pp. 1152-8, May 2003.

[10] K. T. Lee, E. J. Yang, S. Y. Lim, J. K. Pyon, G. H. Mun, S. I. Bang, et al., "Association of congenital microtia with environmental risk factors in South Korea," Int J Pediatr Otorhinolaryngol, vol. 76, pp. 357-61, Mar 2012

[11] M. J. Nieuwenhuijsen, P. Dadvand, J. Grellier, D. Martinez, and M. Vrijheid, "Environmental risk factors of pregnancy outcomes: a summary of recent meta-analyses of epidemiological studies," Environ Health, vol. 12, p. 6, 2013.

[12] K. Buckles and M. Guldi, "Worth the Wait? The Effect of Early Term Birth on Maternal and Infant Health," J Policy Anal Manage, vol. 36, pp. 748-72, 2017.

[13] K. Singh, K. Krishnamurthy, C. Greaves, L. Kandamaran, A. L. Nielsen, and A. Kumar, "Major congenital malformations in barbados: the prevalence, the pattern, and the resulting morbidity and mortality," ISRN Obstet Gynecol, vol. 2014, p. 651783, 2014.

[14] A. Dursun, A. Zenciroglu, N. Hakan, N. Karadag, B. S. Karagol, B. Aydin, et al., "Distribution of congenital anomalies in a neonatal intensive care unit in Turkey," $J$ Matern Fetal Neonatal Med, vol. 27, pp. 1069-74, Jul 2014.

[15] N. Kamal, N. Othman, and A. Salih, "Incidence and Types of Congenital Heart Diseases among Children in Sulaimani Governorate," Kurdistan Journal of Applied Research, vol. 2, pp. 106-111, 2017.

[16] M. Naghavi-Behzad, M. Alizadeh, S. Azami, S. Foroughifar, K. Ghasempour-Dabbaghi, N. Karzad, et al., "Risk Factors of Congenital Heart Diseases: A CaseControl Study inNorthwest Iran," J Cardiovasc Thorac Res, vol. 5, pp. 5-9, 2013

[17] A. H. Bui, A. Ayub, M. K. Ahmed, E. Taioli, and P. J. Taub, "Association Between Cleft Lip and/or Cleft Palate and Family History of Cancer: A Case-Control Study," Ann
Plast Surg, Jan 312018

E. B. Dupepe, D. M. Patel, B. G. Rocque, B. Hopson, A. A. Arynchyna, E. R. Bishop, et al., "Surveillance survey of family history in children with neural tube defects," $J$ Neurosurg Pediatr, vol. 19, pp. 690-695, Jun 2017.

[19] S. Ly, M. L. Burg, U. Ihenacho, F. Brindopke, A Auslander, K. S. Magee, et al., "Paternal Risk Factors for Oral Clefts in Northern Africans, Southeast Asians, and Central Americans," Int J Environ Res Public Health, vol. 14, Jun 192017.

[20] M. J. Khoury, J. D. Erickson, J. F. Cordero, and B. J. McCarthy, "Congenital malformations and intrauterine growth retardation: a population study," Pediatrics, vol. 82, pp. 83-90, Jul 1988 .

[21] U. B. Wennerholm, C. Bergh, L. Hamberger, K. Lundin, L. Nilsson, M. Wikland, et al., "Incidence of congenital malformations in children born after ICSI," Hum Reprod, vol. 15, pp. 944-8, Apr 2000.

[22] L. E. Frederiksen, A. Ernst, N. Brix, L. L. Braskhoj Lauridsen, L. Roos, C. H. Ramlau-Hansen, et al., "Risk of Adverse Pregnancy Outcomes at Advanced Maternal Age," Obstet Gynecol, Feb 52018 .

[23] K. R. Goetzinger, A. L. Shanks, A. O. Odibo, G. A. Macones, and A. G. Cahill, "Advanced Maternal Age and the Risk of Major Congenital Anomalies," Am J Perinatol, vol. 34, pp. 217-222, Feb 2017.

[24] Y. Ingrid Goh, E. Bollano, T. R. Einarson, and G. Koren, "Prenatal multivitamin supplementation and rates of congenital anomalies: a meta-analysis," J Obstet Gynaecol Can, vol. 28, pp. 680-689, Aug 2006.

[25] J. Nazer Herrera, M. Garcia Huidobro, and L. Cifuentes Ovalle, "[Congenital malformations among offspring of diabetic women]," Rev Med Chil, vol. 133, pp. 547-54, May 2005 .

[26] J. Rankin, P. W. Tennant, K. J. Stothard, M. Bythell, C. D. Summerbell, and R. Bell, "Maternal body mass index and congenital anomaly risk: a cohort study," Int J Obes (Lond), vol. 34, pp. 1371-80, Sep 2010.

[27] A. Garcia-Patterson, L. Erdozain, G. Ginovart, J. M Adelantado, J. M. Cubero, G. Gallo, et al., "In human gestational diabetes mellitus congenital malformations are related to pre-pregnancy body mass index and to severity of diabetes," Diabetologia, vol. 47, pp. 509-514, Mar 2004

[28] K. J. Stothard, P. W. Tennant, R. Bell, and J. Rankin, "Maternal overweight and obesity and the risk of congenital anomalies: a systematic review and meta-analysis," JAMA, vol. 301, pp. 636-50, Feb 112009.

[29] S. Johansson, E. Villamor, M. Altman, A. K. Bonamy, F. Granath, and S. Cnattingius, "Maternal overweight and obesity in early pregnancy and risk of infant mortality: a population based cohort study in Sweden," BMJ, vol. 349, p. g6572, Dec 22014.

[30] Z. Mosayebi and A. H. Movahedian, "Pattern of congenital malformations in consanguineous versus nonconsanguineous marriages in Kashan, Islamic Republic of Iran," East Mediterr Health J, vol. 13, pp. 868-75, JulAug 2007. 